\title{
Discussion on China's Marxist Ideological Marginalization under the Network Background
}

\author{
Shuangyin $\mathrm{Li}$ \\ The National Police University for Criminal Justice, \\ Baoding 071000, Hebei \\ Baihong Li \\ Baoding University, \\ Baoding 071000, Hebei \\ Yanjie Hao \\ The National Police University for Criminal \\ Justice, Baoding 071000, Hebei
}

\begin{abstract}
In recent years, the network development is accelerated. In this background, there are new opportunities and serious challenges for the further development of the Marxist ideology. In the process of constantly strengthened network openness, the advantage of the Marxism ideology discourse power has been severely weakened, and simultaneously the relatively strong and hidden western awareness of the network also has caused serious impact on the value domain of China. Under the action of the network medium, the misunderstood or misinterpreted Marxism rapidly spreads, and then the great image of Marxism is seriously affected. Meanwhile, different social problems concentrated on the network also exert a great negative impact on the Marxism belief. Marxist ideology in China, therefore, has faced the crisis of marginalization under the network background. The targeted measures are necessarily adopted to continuously improve the ideology of Marxism and ensure it to stably and sustainably develop.
\end{abstract}

Keywords-Network Background; Marxism; Ideology; Marginalization; Problems

\section{Introduction}

As is known to all, the Marxism ideology in the socialism ideology is the most essential and plays a role of soul, and therefore, its dominant position is necessarily protected, so that the socialist ideological foundation and spiritual pillar are more stable and consolidated. However, the Marxist ideological dominance is not independent, and the full play to its maintenance and dominant role needs the assistance from multiple parties. However, it is facing with a grim security problem on the premise of the rapidly developed Internet technology. The Marxism ideology is marginalized if the above mentioned problems are not effectively responded. Therefore, to take effective measures for ensuring the dominant position of the Marxism ideology is of practical significance to some extent.

\section{New opportunities for the Marxist ideology under the network background}

With the continuous development of the network information technology, network has become the most influential information dissemination medium, so the network is the main form of the Marxist ideology dissemination [1].

The traditional Marxism dissemination forms include books publishing, broadcasting and TV programs, or movies, and also classroom teaching and special reports. However, the above dissemination forms feature a small amount of information and also are greatly limited in many aspects such as disseminated contents, speeds, forms, and timeliness; the interactivity is relatively poor. Under the network background, network media is the key method and carrier of the Marxism popularization and dissemination.

The information amount on the network is very great and the information dissemination speed is extremely fast; information is updated timely; the open and interactive characteristics 
are very obvious, thus providing favorable conditions for the communication of the Marxism in China. First, the network storage function is powerful to store the related research achievements and works in optical and magnetic mediums in the digital form and also spread very rapidly. Second, the expressive forms of the network are three-dimensional; voice, text, video, animation and image are integrated together; the theoretical knowledge is converted to a vivid form, thus aiming to enhancing its influencing power. Third, the network dissemination is obviously interactive; the traditional way is effectively changed, to give a full play to the dominant position of people.

The further development of the network plays an important effect on the further dissemination and development of the Marxism and also provides a great opportunity for the realization of the dominant position of the Marxist ideology. Therefore, it is imperative to correctly promote the Marxism ideology by the correct application of the network and carry out the educational activities.

\section{The marginalization risk of the Marxist ideology under the network background}

\subsection{Seriously weakened discourse power advantage}

Before the emergence of the network technology, a centralized and unified information control model had been formed under the influence of the traditional communication system, so the party and the government could control the mass media to some extent, carefully screen specific information contents, and prevent China's ideology security to be threatened [2]. However, in the process of the rapid development of network technology, a great impact is exerted on the ideology. Because the interactivity, openness and information diversity of the network are obvious, the discourse power advantage of the Marxism ideology has been seriously weakened, and its dominance is being shaken.

\subsection{Serious impact from the powerful hidden western network ideology on the value field of China}

In the Internet environment, most software tools are produced in the United States, so the western developed countries have a great advantage in the network transmission of China-the bourgeois values are universally used through the network and more seriously racialism and religious hostility may permeate. Thus, the ideology of the netizens is changed through a subtle influence, and ultimately a serious impact is exerted on the value field of China and the cohesion and influence of the Marxism mainstream ideology are weakened.

\subsection{The relatively weak network base of the Marxist ideology}

The popularity of the network in China is not long, so the support of capitals, technology, and talents is still short in the process of creating the network base, even if related department attaches great importance to the ideological education. On this basis, the network transmission is not experienced, so there are a few professional websites to publicize and promote the Marxism mainstream ideology, and also the quality is not less standard. The practical survey result showed that the Marxism related websites are browsed by a few people, and also many contents are not effectively consulted [3].

\subsection{Misunderstanding the Marxism image and misinterpreting the serious impact on the Marxism network transmission}

The most important foundation of the Marxism theory lies in the labor value theory. But element theory is produced, and its main argument is that essential productive factors can create valuesthis is essentially a misunderstanding of the Marxism even through it seems to be a development of Marxism on the surface. Moreover, the people, misunderstanding or misinterpreting the Marxism, have weak theoretical foundation or a political purpose. 


\subsection{Serious impact from the network focused social problems on the Marxist belief}

At present, the country is in the opportunity period of the development, but simultaneously social contradictions are prominent. On the basis, the contradiction between social classes and the contradiction between officials and common people are more intensified, thus posing a restriction on the development of the society to a certain extent. On the network, the number of the audiences is large, and also many focused negative problems can attract the people's attention and comments and every aspect of the society is spreading, so that the dominant values of the people are opposite and the Marxism ideology in China is facing a marginal risk.

\section{Ways of effectively maintaining the Marxist ideological dominance under the network background}

\subsection{Promoting the construction of the network base}

The related departments should attach great importance to the network media, actively speed up the construction of the network base, scientifically formulate systemic Internet development strategies, strengthen the further researches of network technology, and construct the professional websites of Marxism by combining with some departments to create network links, thus constantly improving the click rate of these websites [4]. The professional websites of Marxism are the main bases to transmit Marxism, and therefore, they are nonprofit websites. The government should provide the powerful supports of funds, technology and talents and set up a composite personnel team responsible for actively building a network platform, thus constantly increasing the persuasion of these websites, promoting more people to recognize, and attracting more people to browse.

\subsection{Strengthening the network public opinion guiding role}

It is necessary to always adhere to the correct network public opinion direction. First, Marxism online publicity is developed for actively guiding people to analyze problems from the angle of Marxism and then maintaining its important position in the network ideology. Second, in the process of information release, the intervention of bad information is absolutely prohibited; the corresponding software and monitoring system is studied in depth, aiming to effectively prevent and filter bad information. The hostile forces at home and abroad are blocked for avoiding them to spread armful information and cause an adverse effect on the country's security and social stability. Third, a network spokesman system is necessarily created. Essentially, the Marxism is gradually developing and growing in the struggles with other wrong ideologies.

\subsection{Establishing sound network laws and regulations}

First, the network management legislation is integrated into the country's law construction, so as to actively establish the network laws and regulations consistent with China's national conditions.

Second, it is necessary to strengthen the supervision and management on the network ideological field, implement effective control, and make related laws and regulations for striking a serious blow at the crime behaviors.

Third, telecom operators and Internet access service providers are strictly managed; the responsibility regulations for the network service providers are constantly improved, to promote them to actively undertake relevant responsibilities. The guidance problems, once they are discovered, are necessarily removed in a timely manner so as to avoid negative effects. 


\subsection{The innovation and development of the Marxism ideology integration function}

Marxism ideology needs to always keep pace with the times; the network transmission function is fully used, so as to make it possess an integration function through a variety of ways [5]. In the meantime, the role of blogs and online BBS is played and also the transmission timeliness and pertinence are secured with a variety of media in the process of transmitting the Marxism and valuing the professional websites.

\subsection{Fulfilling the Marxism faith's commitment}

To destroy the non-Marxism and anti-Marxism thoughts on the network, the most important is to secure that the party and the government fulfill the faith's commitment in the real life and provide high quality service for the people, thus promoting all the people to be benefited by the fruits of economic development.

\section{Conclusion}

Under the network background, to maintain the dominant position of the Marxism ideology is of important practical significance. In this paper, the opportunities and marginalization risks from the network to the Marxism ideology are specifically analyzed; the effective ways to maintain its leading position are expounded, aiming to further promote the further development of the Marxism ideology in the country.

\section{References}

[1] Jingxian Yang. China's Marxist Ideology Marginalization and Maintenance under the Network Era [J]. Theoretical Journal, 2011 (7): 33-35.

[2] Guiyun Gao, Zhaorui Wang. Study on the Marxist Ideology Marginalization and the Countermeasures under the New Media Environment [J]. Journal of Shihezi University (Philosophy and Social Sciences Edition), 2012, 26 (3): 56-60.

[3] Kun Zhang, Wenjia Zhang. Analysis on the Marxist Ideology Marginalization Crisis [J]. Journal of Hubei Institute of Socialism, 2013 (1): 63-66.

[4] Yonghua Wang. Study on the Marxist Ideology Marginalization Cause Analysis and Countermeasures [J]. Journal of Sichuan Administration Institute, 2010 (2): 48-50.

[5] Bo Li. The current situation of the Marxist Ideology Marginalization Crisis and the Protection $[\mathrm{J}]$. Journal of Shangqiu Vocational College Journal, 2012, 11 (4): $10-11$. 